\title{
Ever the diplomat
}

\section{Science diplomacy matters, and there are capable advocates in the world's scientific societies.}

The UK's Royal Society celebrates its 350th anniversary this year. A group of keen natural philosophers, including Christopher Wren and Robert Boyle, convened its first meeting on 28 November 1660, and thereafter gathered regularly to discuss science and observe experiments, which were curated by Robert Hooke. By 1663, the group had received the endorsement of King Charles II and become known as 'The Royal Society of London for Improving Natural Knowledge'.

Counting among its past presidents such figures as Newton, Kelvin and Rutherford, the Royal Society enjoys a rich history and a bounteous archive. Documents from that archive previously only accessible by academics are being added to a new online collection $^{1}$ that is available to all. Among them are such gems as William Stukeley's Memoirs of Newton's Life, including the tale of the apple that fell from a tree (pictured), Thomas Paine's design for an iron bridge and John Locke's 1681 draft of the Constitutions of Carolina.

However, the role of an academic society has changed markedly in those 350 years, and the fascinations of the past do not define the future. But the Royal Society, with other scientific societies around the world, is finding a way forward. The latest marker on that path was a meeting, hosted last month by the Royal Society, of the InterAcademy Panel $^{2}$ (IAP).

The IAP - a considerably younger organization, founded in 1993 - counts 103 of the world's scientific academies as members (the most recent additions being the Academies of Science of Afghanistan, Mozambique and Nicaragua). The panel assembles once every three to four years, and met this time, in conjunction with an expert conference, to discuss biodiversity - an issue, like climate change or nuclear proliferation, of global significance that hinges crucially on scientific knowledge, and the gaps in that scientific knowledge.

The IAP initiative is typical of the approach espoused in a newly published report ${ }^{3}$, entitled New Frontiers in Science Diplomacy: Navigating the Changing Balance of Power, which summarizes a two-day meeting organized last year by the Royal Society and the American Association for the Advancement of Science. The report stresses the vital role of science diplomacy in the modern world (even if the concept is

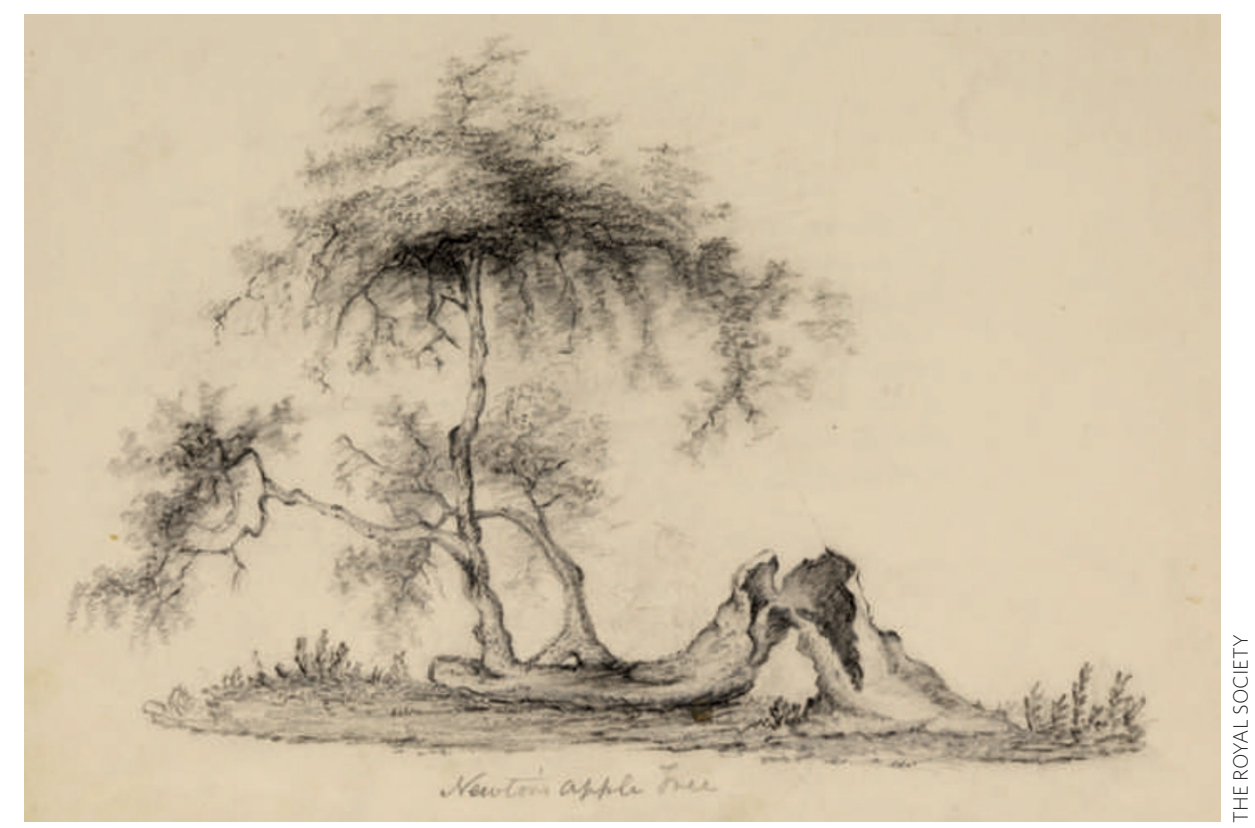

Newton's apple tree. In his Memoirs of Newton's Life of 1752, William Stukeley recorded Newton's anecdote about the falling apple that led him to his theory of gravitation: "Why should that apple always descend perpendicularly to the ground, thought he to himself." Stukeley's manuscript, held by the Royal Society, is now available online?

not a new one - the Royal Society appointed its first Foreign Secretary in 1723, nearly 60 years before the British government saw fit to appoint its own Secretary of State for Foreign Affairs), and "attempts to define this role, and to demonstrate how scientists, diplomats and other policymakers can make it work in practice."

Three 'dimensions' are identified: science in diplomacy, diplomacy for science, and science for diplomacy. The first of these relates to the obvious need for scientific advice and evidence to underpin international negotiations or developments, a prominent example being the work of the existing Intergovernmental Panel on Climate Change. Diplomacy for science recognizes that "science can be a bridge to communities where political ties are weaker, but to develop relationships in these areas, scientists may require diplomatic assistance, whether in contract negotiations, intellectual property agreements or dealing with visa regulations."

Finally, science for diplomacy acknowledges the 'soft power' of science, as a national asset and a universal good - and exemplified by the founding of CERN in post-war, divided Europe. Following the CERN model is the current project to build the synchrotron SESAME in Jordan, as a partnership between several Middle Eastern countries including Israel, Iran and the Palestinian Authority. Indeed the further development of scientific partnerships with the Middle East and the wider Islamic world is identified in the report as a priority for science diplomacy.

The report also supports an earlier call to form an 'Intergovernmental Panel on Nuclear Disarmament', similar to the panel for climate change. With the Review Conference of the Nuclear Non-Proliferation Treaty set to take place in May this year, it is clear that there are scientific and technical issues to be tackled, and such a panel could set out the necessary research agenda - internationally, and for nuclear and non-nuclear states alike. There is work to do, and the world's scientific societies, however ancient or modern, are well placed to lead the effort.

\footnotetext{
References

1. http://royalsociety.org/Turning-the-Pages

2. http://www.interacademies.net

3. http://royalsociety.org/New-frontiers-in-science-diplomacy
} 